\title{
Gefitinib maintenance therapy in Chinese advanced-stage lung adenocarcinoma patients with EGFR mutations treated with prior chemotherapy
}

\author{
K. C. CAI ${ }^{1, \star}$, D. G. LIU $^{1}$, Y. Y. WANG ${ }^{2}$, H. WU ${ }^{1}$, Z. Y. HUANG ${ }^{1}$, R. J. CAI ${ }^{1}$, H. F. WANG ${ }^{1}$, G. XIONG ${ }^{1}$, Z. L. ZHANG \\ ${ }^{1}$ Department of Cardiothoracic Surgery, Nan fang Hospital, Southern Medical University, Guangzhou 510515, China; ${ }^{2}$ Department of Medical \\ Oncology, Nan fang Hospital, Southern Medical University, Guangzhou 510515, China \\ *Correspondence: Doc_cai@163.com
}

Received February 17, 2014 / Accepted August 6, 2014

\begin{abstract}
The aim of this study was to determine the response of advanced-stage non-small cell lung cancer (NSCLC) patients with or without EGFR mutations to platinum-based chemotherapy with or without gefitinib maintenance. Patients were treated with four cycles of platinum-based chemotherapy. Patients with wild-type EGFR were observed (group 1; n=15). EGFR mutation-positive patients were randomly assigned to observation (group $2 ; n=7$ ) or gefitinib maintenance (group $3 ; n=7$ ). The median patient age was 59 years. The 1 -year progression-free survival rates in groups 1,2 , and 3 were $6.7 \%, 28.6 \%$, and $57.1 \%$, respectively $(p=0.049)$; the 1 -year overall survival rates were $53.3 \%, 57.1 \%$, and $100 \%$, respectively $(p=0.111)$. The results indicate that patients with advanced-stage NSCLC with EGFR mutations have a better response to chemotherapy followed by gefitinib than chemotherapy alone and a better response to chemotherapy than wild-type patients.
\end{abstract}

Key words: chemotherapy, gefitinib, NSCLC, tyrosine kinase inhibitors

Of all malignancies, lung cancer has the highest mortality rate worldwide. The World Health Organization (WHO) that reports the worldwide incidence of newly diagnosed lung cancer is over 1.2 million people annually [1]. Over the past 20 years in China, lung cancer has had the greatest increase in incidence and mortality of all malignancies in both urban and rural areas. The 5-year survival rate of lung cancer patients is only $5-7 \%$, and $80 \%$ of patients die within one year of diagnosis [2].

Lung cancer originates from bronchial mucosal epithelial cells and is classified into two histopathological types: nonsmall cell lung cancer (NSCLC; about 85\%) [3] and small cell lung cancer (SCLC; about 15\%) [4]. NSCLC tumors are histologically categorized into several major types: adenocarcinoma, squamous cell carcinoma, large-cell carcinoma, and pleomorphic, sarcomatoid, or sarcomatous carcinoma [3]. Current treatment for lung cancer includes surgery, chemotherapy, and radiotherapy. However, for patients with advanced-stage NSCLC (stages IIIB and IV), treatment is limited to chemotherapy or local radiotherapy. Platinum based chemotherapy is considered the standard first-line treatment for advanced NSCLC. Clinical trials have also shown that combining agents, such as taxanes and gemcitabine, with platinum compounds for chemotherapy have superior efficacy for NSCLC [5].

The epidermal growth factor receptor (EGFR) signaling pathway plays an important role in the regulation of proliferation, growth, and differentiation of normal cells, and EGFR is expressed in epithelial, interstitial, and neurogenic tissues [6]. Studies have shown that EGFR is overexpressed in a variety of tumor cells. In NSCLC, EGFR overexpression is observed in squamous cell carcinomas (70\%) and adenocarcinomas (50\%), whereas in SCLC EGFR is rarely expressed [7]. It has also been shown that EGFR mutations are more prevalent in lung adenocarcinomas that are well-differentiated than those that are poorly differentiated [8]. Although EGFR mutations are dispersed throughout the entire tyrosine kinase coding region, $88 \%$ of the mutations are a deletion in exon 19 and a point mutation in exon 21 (L858R) [9].

The tyrosine kinase inhibitors (TKIs) gefitinib and erlotinib have been shown to be effective in patients with advancedstage lung cancer, and the efficacy of TKIs in NSCLC patients 
with EGFR mutations has been shown to be greater than in NSCLC patients without EGFR mutations [10-13]. Gefitinib and erlotinib function by competing with the binding of adenosine triphosphate (ATP) at the tyrosine kinase ATP binding site in the EGFR intracellular domain. This action stops EGFR signal transduction and inhibits tumor growth [14]. EGFR mutations result in structural changes to the intracellular domain that allows TKIs to bind more easily, and thus increase drug sensitivity [6,7]. Clinical trials have also demonstrated that gefitinib has a better effect than chemotherapy in NSCLC patients who have EGFR mutations [15,16]. A recent review of maintenance therapy with gefitinib after first-line chemotherapy in Chinese patients with NSCLC indicated that regardless of EGFR mutation status, the median overall survival (OS) and progression-free survival (PFS) were 13.1 months and 7.88 months, respectively [17]. In addition, one report has indicated that EGFR mutations may enhance the clinical effect of chemotherapy [18].

The aim of this study was to determine if patients with EGFR mutations have a better therapeutic response to platinumbased chemotherapy than wild-type EGFR patients, and if patients with EGFR mutations have a better therapeutic response to platinum-based chemotherapy followed by gefitinib treatment than platinum-based chemotherapy alone.

\section{Patients and methods}

Patient selection. Thirty-one patients with stage IIIB or IV NSCLC (defined as advanced-stage NSCLC based on the TNM staging standard modified by the Union for International Cancer Control (UICC) in 2009) were recruited from the Southern Medical University's affiliated Southern Hospital from October 2010 to May 2011. In all cases the diagnosis of NSCLC was confirmed by pathological or cytological findings. All patients had received no prior chemotherapy or radiotherapy, and all had performance status (PS) scores $<2$. This study was approved by the Institutional Review Board, and all patients provided written informed consent.

EGFR Mutation analyses. Gene fragments of exons 19-21 were amplified by polymerase chain reaction. The presence of EGFR mutations was detected using the AmoyDx EGFR Mutation Test Kit (Amoy Diagnostics) that can detect 29 mutations in the EGFR gene including an exon 19 deletion, 21L858R, 18G719X, 20S768I, exon 20 insertion, 20T790M, and 21L861Q. PCR was performed according to the manufacturer's instructions and reaction conditions were: 1 ) denaturation at $94^{\circ} \mathrm{C}$ for $5 \mathrm{~min}, 3$ ) annealing at $72^{\circ} \mathrm{C}$ for $20 \mathrm{~s}$, and 4) extension at $72^{\circ} \mathrm{C}$ for 5 minutes.

Clinical treatment and outcome measures. After determination of EGFR mutation status, patients were assigned to one of three treatment groups. Patients with wild-type EGFR were treated with four cycles of a platinum-based chemotherapy, a combination of Cisplatin $\left(80-120 \mathrm{mg} / \mathrm{m}^{2}\right.$ body surface area) and Paclitaxel injection (Taxol, 135-250 $\mathrm{mg} / \mathrm{m}^{2}$ body surface area), once every three weeks (group
1). EGFR mutation-positive patients received four cycles of platinum-based chemotherapy, the same as in group 1, once every three weeks. These patients were then randomly assigned to either observation post-chemotherapy (group 2) or gefitinib maintenance therapy of $250 \mathrm{mg} /$ day by oral administration (group 3) until disease progression or the development of intolerable side effects. Prior to each cycle of chemotherapy, patients received a chest X-ray or contrast-enhanced chest computed tomography (CT) scan. After treatment, patients received a chest X-ray or contrast-enhanced chest CT scan every two months.

All patients were followed for 12 months, or until death. Outcome measures were progression-free survival (PFS) and overall survival (OS). PFS was defined as the time from completion of chemotherapy until disease progression was noted, and OS indicated the percentage of individuals in the group who were alive after a particular duration of follow-up.

Statistical analyses. Due to the small sample size, continuous and categorical variables were compared by MannWhitney U test and chi-square/Fisher's exact test, respectively. Continuous variables were presented as median and interquartile range (IRQ), while categorical data were represented by numbers and percentages. Because gender and smoking were considered to be confounders, Cox proportional hazards regression was performed to characterize survival, including PFS and OS, among the treatment groups over time after adjusting confounding factors. Survival rates were analyzed at 12 months. All statistical assessments were two-sided, and a $p<0.05$ was considered statistically significant. Statistical analyses were performed using SPSS software, version 15.0 (SPSS Inc, Chicago, IL, USA).

\section{Results}

Patient characteristics and EGFR mutation status. Patient data are summarized in Table 1, and EGFR mutation profiles are summarized in Table 2 . The study included 23 males and 8 females with a median age of 59 years (range, $43-77$ years) with stage IIIB or IV NSCLC. Of the 31 patients, $15(48.4 \%)$ had EGFR mutations (8 of 23 males, 7 of 8 females), and 18 (58.1\%)

Table 1. Patient characteristics and EGFR mutation status

\begin{tabular}{lcccc}
\hline & $\begin{array}{c}\text { Total } \\
(\mathrm{N}=31)\end{array}$ & $\begin{array}{c}\text { EGFR Mutations } \\
(n=15)\end{array}$ & $\begin{array}{c}\text { Wild-Type EGFR } \\
(n=16)\end{array}$ & -value \\
\hline${\text { Age, } \mathrm{y}^{1}}$ & $59(43-77)^{\mathrm{a}}$ & $61(57-64)$ & $57.5(55-64.5)$ & 0.406 \\
Gender $^{2}$ & & & & \\
Male & $23(74.2)^{\mathrm{b}}$ & $8(34.8)$ & $15(65.2)$ & $0.015^{*}$ \\
Female & $8(25.8)$ & $7(87.5)$ & $1(12.5)$ & \\
Smoking & & & & \\
Yes & $18(58.1)$ & $6(33.3)$ & $12(66.7)$ & $0.048^{*}$ \\
No & $13(41.9)$ & $9(69.2)$ & $4(30.8)$ & \\
\hline
\end{tabular}

Data are presented as ${ }^{a}$ interquartile range or ${ }^{\mathrm{b}}$ percentage.

$p$-values are based on: ${ }^{1} \mathrm{Mann}$-Whitney $\mathrm{U}$ test; ${ }^{2}$ Fisher's exact test; and ${ }^{3} \mathrm{Chi}$ square test.*, $p<0.05$ 

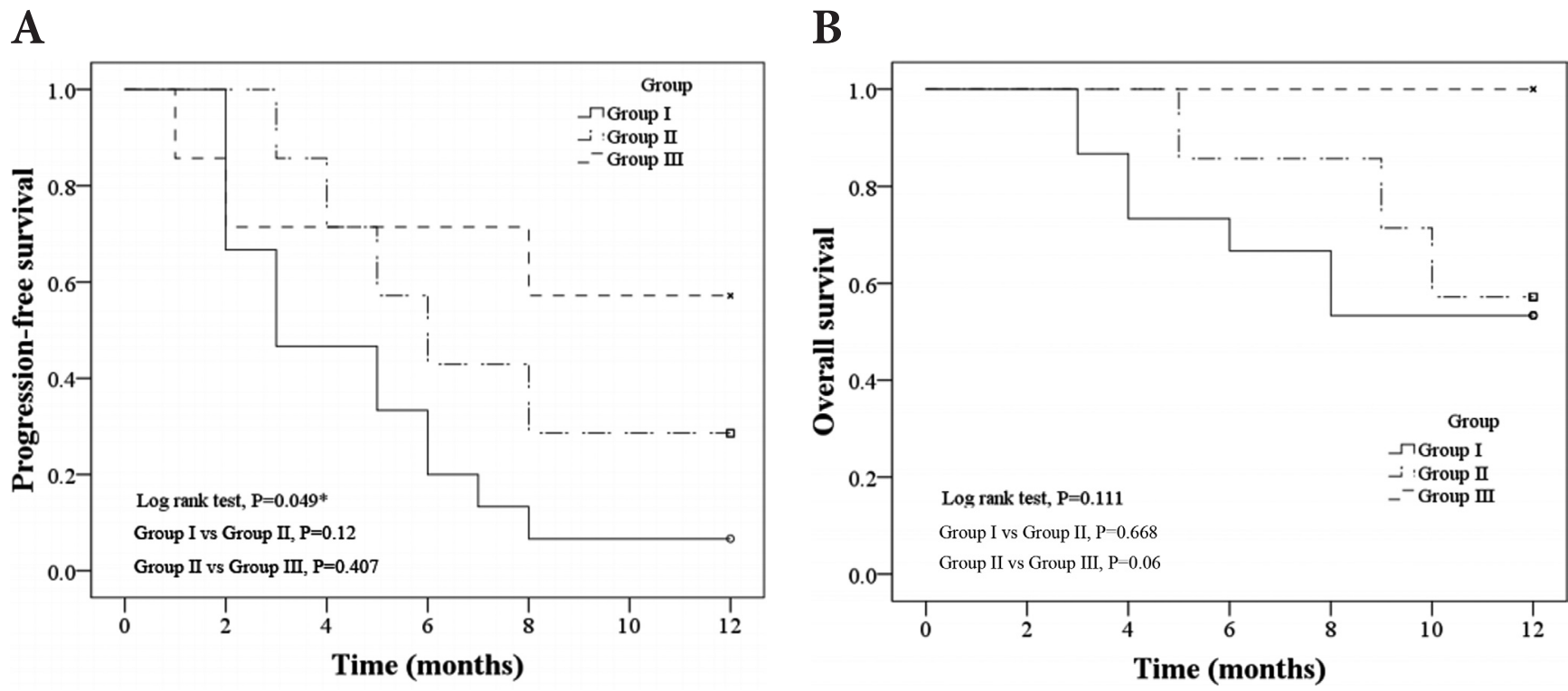

Figure 1. A) Progression-free survival and (B) overall survival of the three treatment groups. Group 1: EGFR wild-type patients treated with platinumbased chemotherapy alone. Group 2: EGFR mutant patients treated with platinum-based chemotherapy alone. Group 3: EGFR mutant patients treated with platinum-based chemotherapy followed by gefitinib therapy.

Table 2. EGFR mutation profile

\begin{tabular}{lcccc}
\hline & \multicolumn{3}{c}{ EGFR Mutations } & Wild-type \\
\cline { 2 - 4 } & exon 19 & exon 21 & ALL & EGFR \\
\hline Lung adenocarcinoma & $8^{\mathrm{a}}(25.8)^{\mathrm{b}}$ & $7(22.6)$ & $15(48.4)$ & $16(51.6)$ \\
Male & $5(21.7)$ & $3(13.1)$ & $8(34.8)$ & $15(65.2)$ \\
Female & $3(37.5)$ & $4(50.0)$ & $7(87.5)$ & $1(12.5)$ \\
Smoking male & $4(22.2)$ & $2(11.1)$ & $6(33.3)$ & $12(66.7)$ \\
Smoking female & 0 & 0 & 0 & 0 \\
Non-Smoking male & $1(20.0)$ & $1(20.0)$ & $2(40.0)$ & $3(60.0)$ \\
Non-smoking female & $3(37.5)$ & $4(50.0)$ & $7(87.5)$ & $1(12.5)$ \\
\hline
\end{tabular}

Data are presented as a sample size and ${ }^{\mathrm{b}}$ percentage.

had a history of tobacco smoking. The EGFR mutation rate was $48.4 \%$ in the 31 lung adenocarcinoma patients, consistent with a reported rate of $40-50 \%[8,9,13]$. The EGFR mutation rate in males was $34.8 \%$, and in females was $87.5 \%$, and the difference was statistically significant $(p<0.05)$. Notably, more non-smokers than smokers had EGFR mutations $(69.2 \%$ vs. $33.3 \%$, respectively; $p=0.048$ ). Patients with the highest $E G F R$ mutation rates were female non-smokers $(87.5 \%)$ and males who smoked tobacco $(33.3 \%)$. This difference in mutation rate was statistically significant $(p<0.05)$.

Survival after treatment. Twenty-nine patients were included in the analysis, as two patients did not survive until the follow-up. Fifteen patients with wild-type EGFR expression were given a platinum-based chemotherapy followed by observation (group 1), seven patients with EGFR mutations were given a platinum-based chemotherapy followed by observation (group 2), and seven patients with EGFR mutations were given a platinum-based chemotherapy followed by gefitinib maintenance (group 3).

There was a statistically significant difference in PFS among the three treatment groups ( $p=0.049$, Fig. 1A). The 1 -year PFS rates for patients in groups 1,2 , and 3 were $6.7 \%$, $28.6 \%$, and $57.1 \%$, respectively. Analysis of OS indicated that there was no significant difference in the OS among the three treatment groups ( $p=0.111$, Fig. 1B). The 1-year OS rates for patients in groups 1,2, and 3 were $53.3 \%, 57.1 \%$, and $100 \%$, respectively.

\section{Discussion}

The results of this study indicate that patients with EGFR mutations have a trend towards a better therapeutic response to platinum-based chemotherapy followed by gefitinib treatment than platinum-based chemotherapy alone (PFS: 57.1\% vs. $28.6 \%$, respectively; OS: $100 \%$ vs. $57.1 \%$, respectively). Furthermore, patients with EGFR mutations had a trend towards a better therapeutic response to chemotherapy than wild-type patients (PFS: $28.6 \%$ vs. $6.7 \%$; OS: $57.1 \%$ vs. $53.3 \%$ ). While the difference in PFS among the three groups was statistically significant ( $p=0.049$ ), the lack of statistical significance in OS ( $p=0.111)$ is likely due to the small sample size.

Clinical trials have demonstrated that gefitinib and erlotinib exhibit better efficacy in advanced-stage NSCLC patients with EGFR mutations than chemotherapy, and carboplatinpaclitaxel has better efficacy in those without EGFR mutations 
[15-17]. In particular, the therapeutic effects of gefitinib are better in patients of Asian decent, non-smokers, and those with adenocarcinoma [19-23]. These populations have been noted to have a higher incidence of EGFR mutations $[13,22]$.

Han et al. [19] reported that $64.7 \%$ (11/17) of NSCLC patients with EGFR mutations responded to gefitinib, while only $13.7 \%$ (10/73) of NSCLC patients with wild-type EGFR had a response. Furthermore, the PFS and OS in patients with EGFR mutations were better than those in patients with wild-type EGFR. In East Asia, the open-label, phase III IRESSA Pan-Asia Study (IPASS) [15] examined the efficacy of first-line gefitinib in 1,217 advanced-stage lung adenocarcinoma patients who were either non-smokers or former light smokers. Patients were randomly divided into two groups who received either gefitinib $(250 \mathrm{mg}$ /day orally) or carboplatin-paclitaxel. The overall PFS rates were $24.9 \%$ for the gefitinib group and $6.7 \%$ for the carboplatin-paclitaxel group. In a subgroup analysis, the PFS of patients with EGFR mutations who received gefitinib was significantly longer than those who received chemotherapy (hazard ratio (HR) for progression or death $=0.48 ; 95 \%$ confidence interval (CI) 0.36-0.64). However, in patients without EGFR mutations the PFS was significantly longer in those that received chemotherapy (HR for progression or death $=2.85,95 \%$ CI 2.05-3.98). In addition, gefitinib was well tolerated with only $6.9 \%$ of patients discontinuing gefitinib due to side effects, as compared to $13.6 \%$ of patients discontinuing chemotherapy.

These data have led to the suggestion that EGFR mutation status should be determined prior to treatment in patients with NSCLC [24,25]. Of note, Sun et al. [26] compared the mutation status of EGFR and KRAS, whose mutations are associated with resistance to TKIs, between primary tumors and local lymph node metastasis in 80 Chinese patients with NSCLC. This study found that the KRAS and EGFR mutation status was different between primary tumors and corresponding metastases in $6(7.5 \%)$ and 7 (8.75\%) of the patients, respectively.

A number of randomized trials have examined the use of TKIs after chemotherapy in patients with NSCLC. The Sequential Tarceva in Unresectable NSCLC (SATURN) trial investigated the use of erlotinib as maintenance therapy in patients with non-progressive NSCLC following first-line platinum-doublet chemotherapy [27]. After a median followup of 11.4 months, the median PFS was significantly longer with erlotinib than with placebo (12.3 weeks vs. 11.1 weeks, respectively, $p<0.0001)$. In EGFR-positive patients, PFS was also significantly longer in those who were treated with erlotinib than those that received placebo. A subanalysis of the SATURN data in Asian patients showed that PFS was also greater in patients that received erlotinib (overall and in those with EGFR mutations), and there was a trend towards increasing overall survival that was statistically significant in EGFR-positive patients [28].
In the West Japan Thoracic Oncology Group trial (WJTOG0203), chemotherapy-naive NSCLC patients were randomly assigned to either six cycles of platinum-doublet chemotherapy or three cycles of platinum-doublet chemotherapy followed by $250 \mathrm{mg} /$ day of oral gefitinib until disease progression. PFS was statistically greater in the gefitinib group, whereas OS results were similar. However, EGFR mutation status was not examined in their study [29]. The INFORM trial randomized patients of east Asian ethnicity with advanced-stage NSCLC who had completed four cycles of first-line platinum-based doublet chemotherapy without disease progression or unacceptable toxic effects to receive gefitinib maintenance or placebo. PFS in EGFR mutant patients was significantly longer in the gefitinib group than in the placebo group (16.6 months vs. 2.8 months, respectively). By contrast, the difference of PFS between the two treatment groups in EGFR wild-type patients was small (2.7 months vs. 1.5 months, respectively) [30]. Consistent with these studies, our study suggests that EGFR mutant patients had a trend towards a better therapeutic response to platinum-based chemotherapy followed by gefitinib maintenance than to chemotherapy alone. In addition, our data also indicates that EGFR mutant patients had a trend towards a better therapeutic response to platinum-based chemotherapy than EGFR wildtype patients.

There are some limitations of this study that should be considered. The number of patients included was small, and the follow-up time was only 12 months. A larger patient cohort and longer follow-up period may result in statistically significant differences between the treatment groups, especially for OS rates.

\section{Conclusions}

The overall percentage of lung cancer patients with EGFR mutations was approximately $50 \%$. Those with the highest EGFR mutation rate $(87.5 \%)$ were female non-smokers, and males who smoked tobacco had an EGFR mutation rate of $33.3 \%$. Patients with EGFR mutations had a trend towards a better therapeutic response to platinum-based chemotherapy followed by gefitinib treatment than to platinum-based chemotherapy alone, and patients with EGFR mutations had a trend towards a better therapeutic response to chemotherapy than wild-type patients. While the difference in PFS among the three groups was statistically significant, the lack of statistical significance in OS was likely due to the small sample size. The results of this study will help to determine optimal therapeutic strategies for advanced-stage lung adenocarcinoma patients, with or without EGFR mutations, particularly those in China.

Acknowledgements: This work was supported by SUB-subject of nationally supportive subject-Research and Application of Appropriate Technology in Control and Prevention of common Diseases in Xinjiang Autonomous Region (grant number: 2013 BAI05B02). 


\section{References}

[1] QING HZ, YAN S. The progress of new theories and technologies in lung cancer. 1st ed. Sichuan, Sichuan Ren Xue Press, 2003. p. 411.

[2] National Research Office of Tumor Prevention and Health statistical Information Center of the Ministry of Health. The incidence and mortality of malignant tumors in pilot cities and counties in China, 2002.volume 2, 1993-1997. Beijing, Chinese Medical Science and Technology Press.

[3] TSVETKOVA E, GOSS GD. Drug resistance and its significance for treatment decisions in non-small-cell lung cancer. Curr Oncol 2012; 19: S45-51.

[4] SHER T, DY GK, ADJEI AA. Small cell lung cancer. Mayo Clin Proc 2008; 83: 355-367. http://dx.doi. org/10.4065/83.3.355

[5] RAMALINGAM S1, BELANI C, ONCOLOGIST. Systemic chemotherapy for advanced non-small cell lung cancer: recent advances and future directions. 2008; 13 Suppl 1: 5-13.

[6] YARDEN Y. The EGFR family and its ligands in human cancer: signaling mechanisms and therapeutic opportunities. Eur J Cancer 2001; 37: S3-8. http://dx.doi.org/10.1016/ S0959-8049(01)00230-1

[7] SCAGLIOTTI GV, SELVAGGI G, NOVELLO S, HIRSCH FR. The biology of epidermal growth factor receptor in lung cancer. Clin Cancer Res 2004; 10: 4227s-4232s. http://dx.doi. org/10.1158/1078-0432.CCR-040007

[8] LIU Y, XU ML, ZHONG HH, HENG WJ, WU BQ. EGFR mutations are more frequent in well-differentiated than in poor-differentiated lung adenocarcinomas. Pathol Oncol Res 2008; 14: 373-379. http://dx.doi.org/10.1007/s12253-0089113-1

[9] PAO W, MILLER V, ZAKOWSKI M, DOHERTY J, POLITI $\mathrm{K}$, et al. EGF receptor gene mutations are common in lung cancers from "never smokers" and are associated with sensitivity of tumors to gefitinib and erlotinib. Proc Natl Acad Sci USA 2004; 101: 13306-13311. http://dx.doi.org/10.1073/ pnas.0405220101

[10] JORISSEN RN, WALKER F, POULIOT N, GARRETT TP, WARD CW, et al. Epidermal growth factor receptor: mechanism of activating and signaling. Exp Cell Res 2003; 284: 31-53. http://dx.doi.org/10.1016/S0014-4827(02)00098-8

[11] SIROTNAK FM, ZAKOWSKI MF, MILLER VA, SCHER HI, KRIS MG. Efficacy of cytotoxic agents against human tumor xenografts is markedly enhanced by coadministration of ZD1839 (Iressa), an inhibitor of EGFR tyrosine kinase. Clin Cancer Res 2000; 6: 4885-4892.

[12] LYNCH TJ, BELL DW, SORDELLA R, GURUBHAGAVATULA S, OKIMOTO RA, et al. Activating mutations in the epidermal growth factor receptor underlying responsiveness of non-small cell lung cancer to gefitinib. N Engl J Med 2004; 350: 2129-2139. http://dx.doi.org/10.1056/ NEJMoa040938

[13] PAEZ JG, JANNE PA, LEE JC, TRACY S, GREULICH H, et al. EGFR mutations in lung cancer: correlation with clinical response to gefitinib therapy. Science 2004; 304: 1497-1500. http://dx.doi.org/10.1126/science.1099314
[14] WAKELING AE, GUY SP, WOODBURN JR, ASHTON SE, CURRY BJ, et al. ZD1839 (Iressa): an orally active inhibitor of epidermal growth factor signaling with potential for cancer therapy. Cancer Res 2002; 62: 5749-5754.

[15] MOK TS, WU YL, THONGPRASERT S, YANG CH, CHU DT, et al. Gefitinib or carboplatin-paclitaxel in pulmonary adenocarcinoma. N Engl J Med 2009; 361: 947-957. http:// dx.doi.org/10.1056/NEJMoa0810699

[16] MITSUDOMI T, MORITA S, YATABE Y, NEGORO S, OKAMOTO I, et al. Gefitinib versus cisplatin plus docetaxel in patients with non-small-cell lung cancer harbouring mutations of the epidermal growth factor receptor (WJTOG3405): an open label randomized phase 3 trial. Lancet Oncol 2010; 11: 121-128. http://dx.doi.org/10.1016/S1470-2045(09)70364-X

[17] BIAOXUE R, SHUANYING Y, WEI L, WEI Z, ZONGJUAN M. Maintenance therapy of gefitinib for non-small-cell lung cancer after first-line chemotherapy regardless of epidermal growth factor receptor mutation: a review in Chinese patients. Curr Med Res Opin 2012; 28: 1699-1708. http:// dx.doi.org/10.1185/03007995.2012.728525

[18] EBERHARD DA, JOHNSON BE, AMLER LC, ET A1. Mutations in the epidermal growth factor receptor and in K-ras are predictive and prognostic indicators in patients with non-small-cell lung cancer treated with chemotherapy alone and in combination with erlotinib. J Clin Oncol, 2005, 23: 5900-5909. http://dx.doi.org/10.1200/JCO.2005.02.857

[19] HAN SW, KIM TY, HWANG PG, JEONG S, KIM J, et al. Predictive and prognostic impact of epidermal growth factor receptor mutation in non-small cell lung cancer patients treated with gefitinib. J Clin Oncol 2005; 23: 2493-2501. http:// dx.doi.org/10.1200/JCO.2005.01.388

[20] VARELLA-GARCIA M, MITSUDOMI T, YATABE Y, KOSAKA T, NAKAJIMA E, et al. EGFR and HER2 genomic gain in recurrent non-small cell lung cancer after surgery: impact on outcome to treatment with gefitinib and association with EGFR and KRAS mutations in a Japanese cohort. J Thorac Oncol 2009; 4: 318-325. http://dx.doi.org/10.1097/ JTO.0b013e31819667a3

[21] TAMURA K, FUKUOKA M. Gefitinib in non-small cell lung cancer. Expert Opin Pharmacother 2005; 6: 985-993. http:// dx.doi.org/10.1517/14656566.6.6.985

[22] MITSUDOMI T, KOSAKA T, YATABE Y. Biological and clinical implications of EGFR mutations in lung cancer. Int J Clin Oncol 2006; 11: 190-198. http://dx.doi.org/10.1007/ s10147-006-0583-4

[23] GRIDELLI C, DE MARINIS F, DI MAIO M, CORTINOVIS D, CAPPUZZO F, MOK T. Gefitinib as first-line treatment for patients with advanced non-small cell lung cancer with activating epidermal growth factor receptor mutation: Review of the evidence. Lung Cancer 2011; 71: 249-257. http://dx.doi. org/10.1016/j.lungcan.2010.12.008

[24] D'INCECCO A, CAPPUZZO F. Gefitinib for non-small cell lung cancer treatment. Expert Opin Drug Saf 2011; 10: 987-996. http://dx.doi.org/10.1517/14740338.2011.617738

[25] GREGORC V, HIDALGO M, SPREAFICO A, CUSATIS G, LUDOVINI V, et al. Germline polymorphisms in EGFR and 
survival in patients with lung cancer receiving gefitinib. Clin Pharmacol Ther 2008; 83: 477-484. http://dx.doi.org/10.1038/ sj.clpt. 6100320

[26] SUN L, ZHANG Q, LUAN H, ZHAN Z, WANG C, et al. KRAS and EGFR gene status between primary non-small cell lung cancer and local lymph node metastases: implications for clinical practice. J Exp Clin Cancer Res 2011; 30: 30. http:// dx.doi.org/10.1186/1756-9966-30-30

[27] CAPPUZZO F, CIULEANU T, STELMAKH L, CICENAS S, SZCZESNA A, et al. SATURN investigators. Erlotinib as maintenance treatment in advanced non-small-cell lung cancer: a multicentre, randomised, placebo-controlled phase 3 study. Lancet Oncol 2010; 11: 521-529. http://dx.doi.org/10.1016/ $\underline{\text { S1470-2045(10)70112-1 }}$

[28] WU YL, KIM JH, PARK K, ZAATAR A, KLINGELSCHMITT G, NG C. Efficacy and safety of maintenance erlotinib in Asian patients with advanced non-small-cell lung cancer: a subanalysis of the phase III, randomized SATURN study. Lung Cancer 2012, 77: 339-345. http://dx.doi.org/10.1016/j.lungcan.2012.03.012

[29] TAKEDA K, HIDA T, SATO T, ANDO M, SETO T, et al. Randomized phase III trial of platinum-doublet chemotherapy followed by gefitinib compared with continued platinum-doublet chemotherapy in Japanese patients with advanced non-small-cell lung cancer: results of a west Japan thoracic oncology group trial (WJTOG0203). J Clin Oncol 2010, 28: 753-760. http://dx.doi.org/10.1200/ LCO.2009.23.3445

[30] ZHANG L, MA S, SONG X, HAN B, CHENG Y, et al. INFORM investigators. Gefitinib versus placebo as maintenance therapy in patients with locally advanced or metastatic non-small-cell lung cancer (INFORM; C-TONG 0804): a multicentre, double-blind randomised phase 3 trial. Lancet Oncol 2012, 13: 466-475. http://dx.doi.org/10.1016/S14702045(12)70117-1 